\title{
Flux for Stronger Solder Joints on Ni-P/Au Electrodes
}

\author{
Seishi Kumamoto*, Hitoshi Sakurai*, Youichi Kukimoto* and Katsuaki Suganuma** \\ *Electronics Materials Division, Research and Development Group Harima Chemicals Inc., Kakogawa, Hyogo 675-0019, Japan \\ **Department of Adaptive Machine Systems, Graduate School of Engineering, Osaka University, Ibaraki, Osaka 567-0047, Japan
}

(Received September 5, 2008; accepted November 25, 2008)

\begin{abstract}
Packaging technologies such as BGA and CSP are now widely used to fabricate high-performance IC packages with everincreasing degrees of miniaturization. In addition, electroless $\mathrm{Ni}$ /flash Au plating is now seeing wide-spread application because it offers improved solder wettability, etc. on electrodes. However, $\mathrm{P}$ tends to concentrate at the interface between the solder and Ni electrode, thereby reducing the joint strength. Despite several studies concentrating on plating methods and solder compositions, no solution to this problem has yet been found. However, through investigations on the use of various soldering fluxes, we successfully mitigated this decrease in joint strength by using a special flux containing $\mathrm{Cu}$ when joining solder balls to electroless $\mathrm{Ni}$ /flash Au-plated lands. Cross-sectional observation of the solder/electrode interface confirmed that the thickness of the concentrated P layer was reduced by the proposed method. We believe that the $\mathrm{Cu}$ ions contained in the flux acted as a barrier to the diffusion of $\mathrm{Ni}$ into the solder, thereby limiting the formation of a concentrated P layer.
\end{abstract}

Keywords: Joint Strength, Electroless Nickel-Phosphorus, Black Pad, Flux, Lead-Free Solder

\section{Introduction}

The current consumer trend toward increased mobility—be it in mobile phones, laptops, or portable DVD players-has translated into a constant demand for increased miniaturization and weight reduction. In response, rapid progress has been made in both the performance and size of electronic equipment through the use of high-density mounting techniques, which have progressed from the perimeter terminals used in quad flat packages (QFPs) to the grid terminals now used in ball grid arrays (BGAs) and chip scale packages (CSPs).

Such high-density techniques are often used in portable equipment, where the reliability of the solder joint used to mount parts onto a printed circuit board is critical. Substrates used in such equipment are often plated with $\mathrm{Ni}$ or $\mathrm{Au}$ to increase their corrosion resistance, oxidation resistance, solder wettability, and electrical conductivity. Today, electroless plating (electroless Ni-P plating) has replaced the previous electroplating method, which involved the complicated process of drawing fine wires.

Though electroless Ni-P/Au plating is an established technology that can achieve the high reliability mentioned above, the reliability of the solder/electrode interface in actual products on the market is a major concern: parts that show high wettability and seem to have excellent joints later fall off the board, and the solder peels off when it is subsequently hand-soldered. Such electrodes are called "black pads" because the flaking surface appears black. This problem has reportedly increased with the recent trend toward the use of lead-free solders.

The decrease in joint reliability with BGA and CSP (bump) and electroless Ni-P/Au plating is assumed to be due to the high reactiveness of lead-free solders. In short, it is thought that the cause of weakness is the concentrated $\mathrm{P}$ layer around the joint interface formed by intermetallic compounds of $\mathrm{Sn}$ and $\mathrm{Ni}[1-8]$; the mechanism of intermetallic compound formation, the structure of the layer, and the relationship among the solder composition, reflow temperature, and Au plating thickness all have been investigated.[9-10]

To address this problem, we focused on the flux used for soldering, not the plating or solder composition. Few studies approach the problem from this viewpoint, despite the fact that the use of soldering flux is an effective and simple measure to improve joint strength.

In this study, we used fluxes containing different metallic compounds in an attempt to improve the joint strength. In addition, we analyzed the solder/electrode interface to 
clarify the mechanism behind the strength improvement.

We focused on the use of a $\mathrm{Cu}$ compound, which we considered would be most effective because:

1) The addition of $\mathrm{Cu}$ can change the state of the joint interface, and $\mathrm{Cu}$ can be expected to control the diffusion of $\mathrm{Ni}$.

2) Substitution reactions can be expected with the electrode metals (e.g., $\mathrm{Ni}$ ) as the ionization potential of $\mathrm{Cu}$ is small.

$$
\mathrm{Ni}+\mathrm{Cu}^{2+} \rightarrow \mathrm{Ni}^{2+}+\mathrm{Cu}
$$

3) Toxicity is not a concern even if $\mathrm{Cu}$ is included in the solder composition.

The new flux proposed herein is referred to as the "barrier flux," because the $\mathrm{Cu}$ ions in the flux form a reactive barrier layer on the Ni surface during soldering. Here we report the improvements in the solder joint strength and observations of the solder/electrode interface produced when the barrier flux is used.

\section{Experiments}

\subsection{Preparation of barrier flux}

Solder balls are mounted on BGA packages by the following processes: 1) flux spreading, 2) solder ball mounting, 3) solder melting, and 4) washing. The flux spreading process mentioned above is performed by the printing method or by the pin transcript method, whereby flux is applied only onto the lands on the substrate. In this study, we used the printing method, which allows easier mounting of the solder balls, and prepared a flux with physical properties appropriate for that method.

Table 1 Flux composition (mass\%)

\begin{tabular}{l|c|c}
\hline Flux & Barrier Flux & Reference Flux \\
\hline Base resin (rosin) & 58.0 & 65.0 \\
\hline Activator (organic acid) & 2.0 & 2.0 \\
\hline Solvent & 27.0 & 30.0 \\
\hline Thixotropic agent & 3.0 & 3.0 \\
\hline Copper compound & 10.0 & 0.0 \\
\hline
\end{tabular}

Table 2 Physical properties of flux

\begin{tabular}{c|c|c}
\hline & Barrier Flux & Reference Flux \\
\hline Viscosity & $60 \mathrm{~Pa} \bullet \mathrm{s}$ & $55 \mathrm{~Pa} \bullet \mathrm{s}$ \\
\hline Tackiness & $160 \mathrm{gf}$ & $160 \mathrm{gf}$ \\
\hline Resistivity of water extract & $1.0 \times 10^{5} \Omega \bullet \mathrm{cm}$ & $1.0 \times 10^{5} \Omega \bullet \mathrm{cm}$ \\
\hline Spread test & $91 \%$ & $91 \%$ \\
\hline
\end{tabular}

The flux used was a mixture of activators (organic acid, amines, and halogenation activators), which remove the oxides on the surface of the solder and for stronger joints, and solvents (IPA, ethanol, and higher alcohols). We simplified the composition of the flux as much as possible to clarify the influence of the added $\mathrm{Cu}$ compound. Moreover, a thixotropic agent was added to the flux to adjust its viscosity so that it could be printed and to adjust its tackiness so that it would attach to the parts. A flux without the $\mathrm{Cu}$ compound (reference flux) was also prepared and the resulting joint strengths were compared. The composition of each flux is shown in Table 1.

The basic physical characteristics of the fluxes were measured according to the methods stipulated in JIS Z 3284 (Table 2). Table 2 shows the physical properties of Flux. We measured 1) viscosity, 2) tackiness, 3) resistivity of water extract, and 4) spread test.

\subsection{Measurement of joint strength}

Solder balls of two different compositions-one including $\mathrm{Cu}$ and the other not including CU-were used in this study to determine the influence of $\mathrm{Cu}: \mathrm{Sn}-3.0 \mathrm{Ag}-0.5 \mathrm{Cu}$ and $\mathrm{Sn}-3.5 \mathrm{Ag}$ (in mass\%; see Table 3). The diameter of the balls was $600 \mu \mathrm{m}$.

BGA substrates with electroless $\mathrm{Au} / \mathrm{Ni}-6$ wt\%P-plated $\mathrm{Cu}$ pads measuring $0.5 \mathrm{~mm}$ in diameter were used. A commonly used, low-middle phosphorus concentration of 6 $w t \%$ was selected as the concentration of the Ni-P plating,. The thicknesses of the Au and Ni-6 wt\%P layers were 0.05 and $5 \mu \mathrm{m}$, respectively. The first step in the preparation of test samples was to screen-print the flux to a thickness of $100 \mu \mathrm{m}$ in regions with a diameter of $0.5 \mathrm{~mm}$. Then, ten solder balls were placed on each sample and the assemblies were subjected to reflow in a $\mathrm{N}_{2}$ atmosphere. The reflow profile had a peak temperature of $250^{\circ} \mathrm{C}$. After the reflow treatment, the assemblies were ultrasonically cleaned in isopropyl alcohol to eliminate any residual flux. The joint pull strength of the soldered balls was evaluated using a hot bump pull (HBP) tester (Dage, Dage Series 4000P). A pull speed of $300 \mu \mathrm{m} / \mathrm{s}$ was used in each HBP test. To measure the shock strength of the solder joints, a microimpact tester (Micro Impact; Yonekura) was used to measure the maximum impact force and the energy

Table 3 Composition of solder balls (mass\%)

\begin{tabular}{lccl}
\hline & $\mathrm{Ag}$ & $\mathrm{Cu}$ & $\mathrm{Sn}$ \\
\hline $\mathrm{Sn}-3.0 \mathrm{Ag}-0.5 \mathrm{Cu}$ & 2.96 & 0.483 & Bal. \\
$\mathrm{Sn}-3.5 \mathrm{Ag}$ & 3.41 & 0.001 & Bal.
\end{tabular}


absorbed on impact. Microimpact tests were performed with a pendulum weight of $100 \mathrm{~g}$ and an impact speed of $1000 \mathrm{~mm} / \mathrm{s}$.

The fracture surfaces of these test samples were examined under a digital microscope (VHX-200; KEYENCE). In addition, some of the test samples were molded in epoxy resin and cross-sectioned for microstructural observation and analysis by scanning electron microscopy (SEM).

\section{Results and Discussion}

\subsection{Pull strength test}

The results of this test for the solder balls of different compositions $(\mathrm{Sn}-3.0 \mathrm{Ag}-0.5 \mathrm{Cu}$ and $\mathrm{Sn}-3.5 \mathrm{Ag})$ are shown in Fig. 1.

Figure 1 shows that the mean pull strength increased (Sn-3.0Ag-0.5Cu, 29\% increase; $\mathrm{Sn}-3.5 \mathrm{Ag}, 19 \%$ increase) when $\mathrm{Cu}$ was added to the flux; the minimum strength also increased ( $\mathrm{Sn}-3.0 \mathrm{Ag}-0.5 \mathrm{Cu}, 73 \%$ increase; $\mathrm{Sn}-3.5 \mathrm{Ag}, 33 \%$ increase). Thus, regardless of the composition of the solder, the addition of $\mathrm{Cu}$ to the flux increases the pull strength of the joint.

\subsection{Microimpact test}

BGA packages are often used in cellular phones, where resilience to dropping impacts is very critical.[11] Impact testing of solder joints investigates and evaluates the damage caused to the solder joint when the mounted package is dropped onto a concrete floor from a prescribed height. The advantage of this test is that the reliability can be
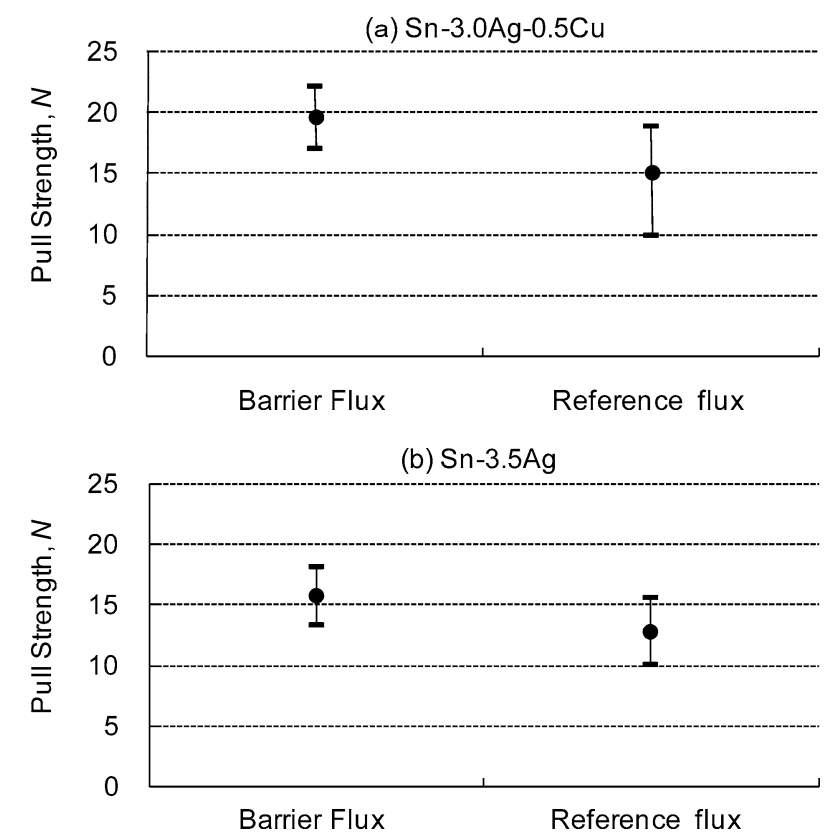

Fig. 1 The pull strengths of solder joints for (a) Sn-3.0Ag$0.5 \mathrm{Cu}$ and $(\mathrm{b}) \mathrm{Sn}-3.5 \mathrm{Ag}$. determined accurately at the product level. However, it is difficult to apply this test to the evaluation of solder materials, substrates, and soldering process conditions because of the time and cost involved in the preparation of evaluation samples. In addition, though shear strength tests can be used to evaluate the impact resistance of such products, the tests are time consuming as they use very slow speeds (several tens of micrometers to several millimeters per second) compared with those used in the dropping impact tests. And, since the major failure mode in shear strength tests is the failure of the solder, this test measures the mechanical properties of the solder itself, and will therefore produce different results from the impact test.[12-13] In contrast, high speeds (1000-2000 mm/s) can be used in microimpact testing, making it more effective for strength measurement as it produces failure modes similar to those in dropping impact tests on products.[14] Microimpact testing was performed instead of shear strength tests, to obtain results more similar to those of dropping impact tests, when performing shear tests.

With the microimpact apparatus, samples can be subjected to impacts at high speed with considerable accuracy, and moreover, the load and displacement can be measured simultaneously. Using this data the energy absorbed on impact and maximum impact load can be calculated. The samples subjected to the pull strength test were also subjected to this test to determine the effect of $\mathrm{Cu}$ addition to the flux.

Figure 2 shows the results of an impact test. Clearly, regardless of the composition of the solder, the addition of $\mathrm{Cu}$ to the flux produces higher average values ( $\mathrm{Sn}-3.0 \mathrm{Ag}-$ $0.5 \mathrm{Cu}, 24 \%$ increase; $\mathrm{Sn}-3.5 \mathrm{Ag}, 14 \%$ increase) and higher minimum values $(\mathrm{Sn}-3.0 \mathrm{Ag}-0.5 \mathrm{Cu}, 14 \%$ increase; $\mathrm{Sn}-$ $3.5 \mathrm{Ag}, 24 \%$ increase). Thus, the addition of the $\mathrm{Cu}$ compound to the flux improves not only pull strength but also shear strength under impact loads.

Figure 3 shows the amount of impact energy absorbed. The addition of the $\mathrm{Cu}$ compound produced higher values and, in the case of $\mathrm{Sn}-3.5 \mathrm{Ag}$ solder balls, a threefold increase. This remarkable difference appears to originate from the existence of small amounts of $\mathrm{Cu}$ during soldering. That is, we considered that the $\mathrm{Cu}$ in the flux enters the solder during the joining process, thereby changing the properties of the solder.

To further investigate the effect of the addition of $\mathrm{Cu}$ to the flux, we observed the fracture surfaces of the solder after the microimpact test under the microscope (Fig. 4). From the figure, it is clear that proportionally more solder 

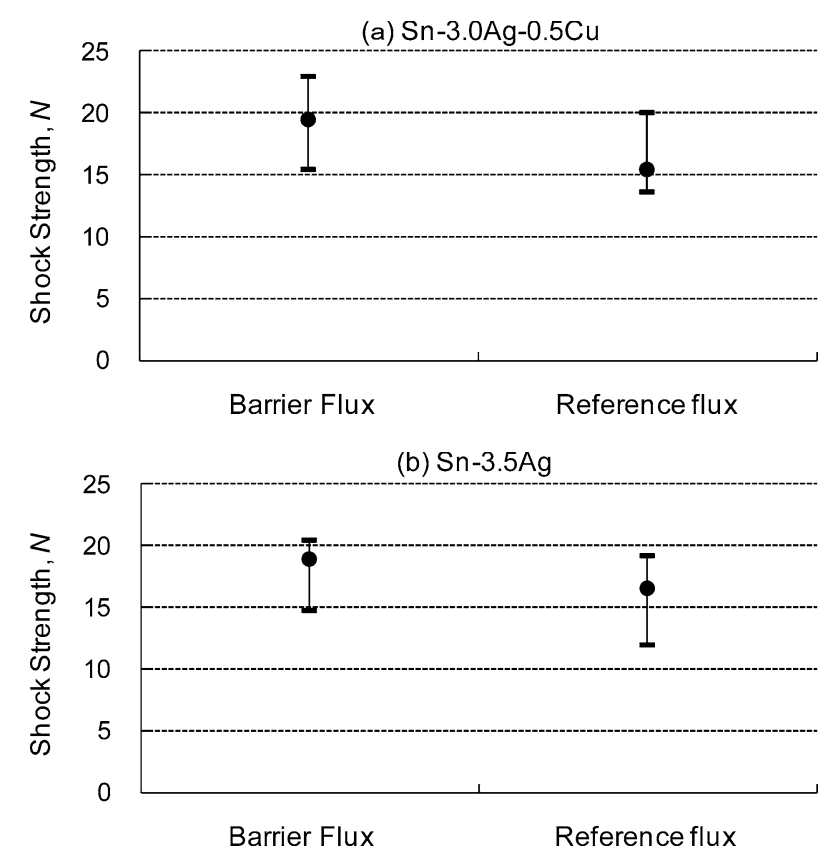

Fig. 2 The shock strength of solder joints for (a) $\mathrm{Sn}-3.0 \mathrm{Ag}-$ $0.5 \mathrm{Cu}$ and (b) Sn-3.5Ag.
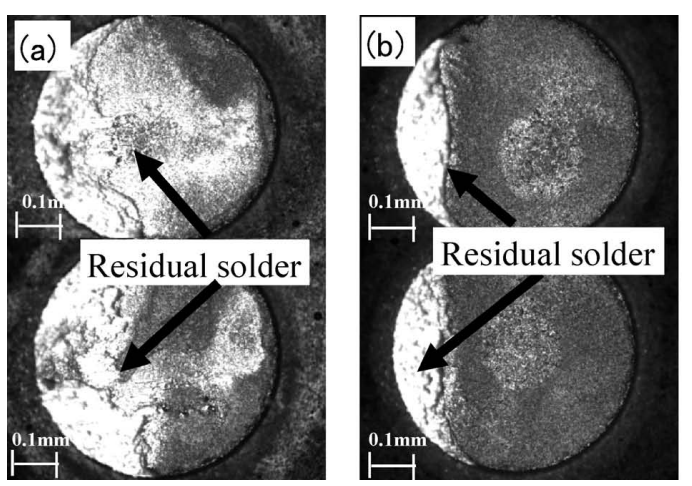

Fig. 4 Fracture surfaces of the samples after microimpact tests: (a) $\mathrm{Sn}-3.0 \mathrm{Ag}-0.5 \mathrm{Cu} / \mathrm{barrier}$ flux, (b) $\mathrm{Sn}-3.0 \mathrm{Ag}-0.5 \mathrm{Cu} / \mathrm{reference}$ flux, (c) Sn-3.5Ag/barrier flux, and (d) Sn-3.5Ag/reference flux. The impact came from the left-hand side for all ball joints.

remains on the electrode when the $\mathrm{Cu}$ compound is added to the flux, regardless of the composition of the solder. This can be assumed to be the reason behind the increase in the strength of the solder joint, allowing the joint to bear higher impact loads and absorb larger amounts of impact energy.

The values of energy absorbed on impact shown in Fig. 3 are stable with lower reference flux, while the values of the flux to which the $\mathrm{Cu}$ compound has been added vary with higher values. It is presumed that this variability manifests as the variability in the amount of residual solder left on the electrodes shown in Fig. 4.

\subsection{Interfacial microstructure}

Figure 5 shows SEM micrographs of a cross section of
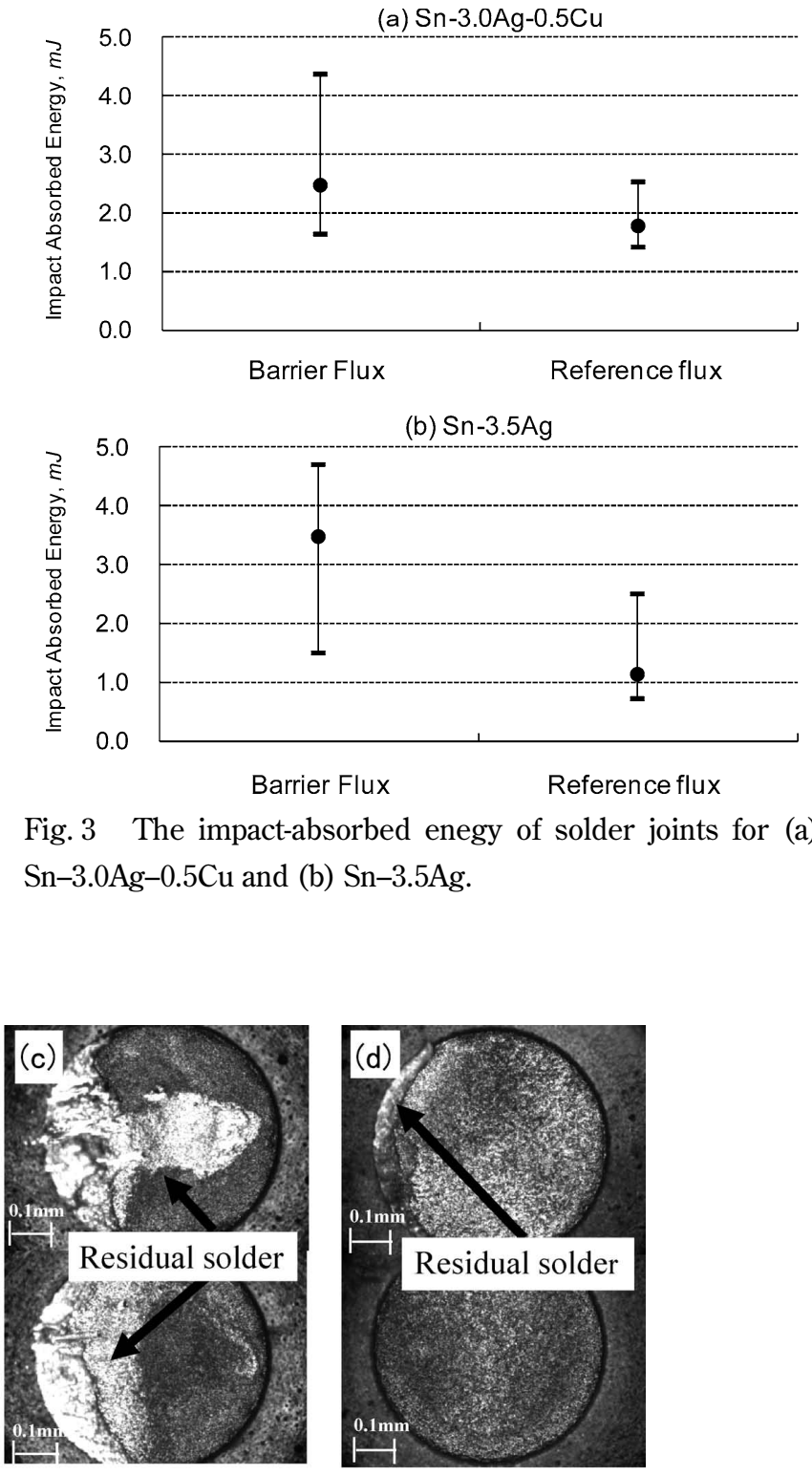

Fig. 3 The impact-absorbed enegy of solder joints for (a) $\mathrm{Sn}-3.0 \mathrm{Ag}-0.5 \mathrm{Cu}$ and (b) Sn-3.5Ag.

the solder/electrode interface.

The black layer at the interface has been reported to be the P-rich layer.[3-4, 7-8] We see that this layer is thinner when the $\mathrm{Cu}$ compound is added, regardless of the solder composition.

The thicknesses of the concentrated P layers shown in Fig. 5 were measured and compared (five-point measurements); the layer was $100-300 \mathrm{~nm}$ thick when $\mathrm{Cu}$ was added to the flux, whereas it was $300-450 \mathrm{~nm}$ and more uneven with the reference flux. It is thought that this decrease in the thickness of the concentrated $\mathrm{P}$ layer is one of the mechanisms that prevent a decrease in joint strength and increase in dispersion. 


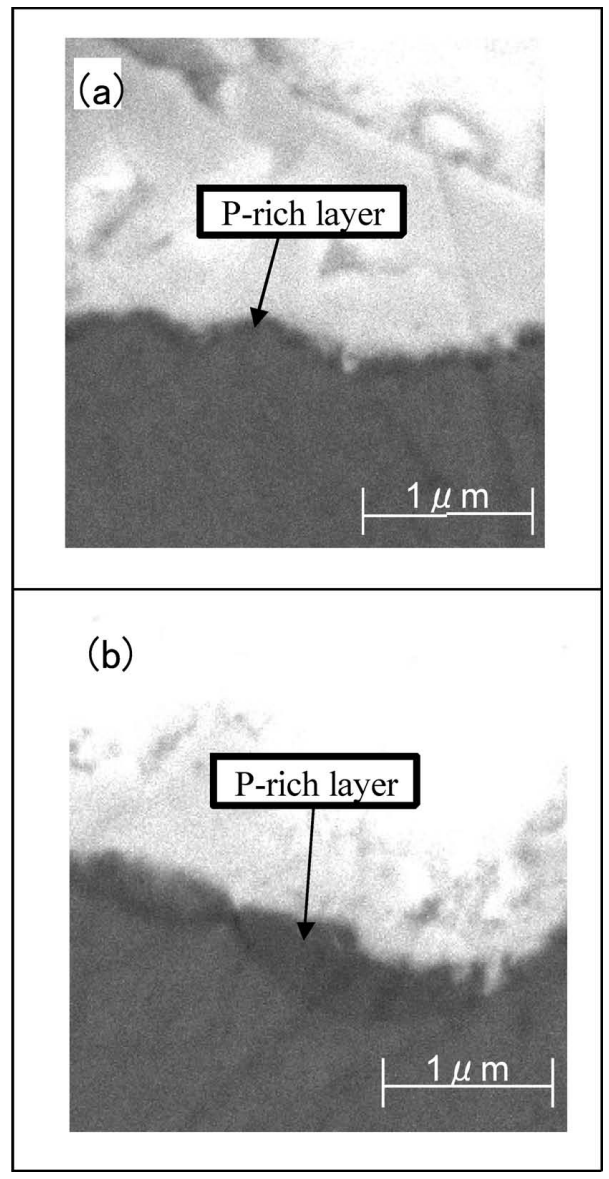

Fig. 5-1 Cross-sectional SEM images of Sn$3.0 \mathrm{Ag}-0.5 \mathrm{Cu}$ solder joint interface for: (a) barrier flux (20,000x); and (b) reference flux $(20,000 x)$.

\section{Conclusions}

This study investigated the joint strength and interfacial structure of solder balls mounted on electroless $\mathrm{Ni}-\mathrm{P}$ electrodes using a flux containing a $\mathrm{Cu}$ compound. The results are as follows:

(1) Joint strength improved with the addition of $\mathrm{Cu}$ to the flux, as seen in measurements of the pull strength, regardless of the solder composition.

(2) This strength improvement was reflected in microimpact testing for both the maximum impact load and absorbed impact energy, which is considered to be directly related to the failure modes seen in dropping impact tests on final products. A remarkable increase was seen when a small amount of $\mathrm{Cu}$ was added to $\mathrm{Sn}-3.5 \mathrm{Ag}$, especially in the absorbed impact energy. It is considered that the presence of the $\mathrm{Cu}$ during soldering caused that remarkable difference.

(3) Observations of the solder/electrode interface revealed that the thickness of concentrated $\mathrm{P}$ layer

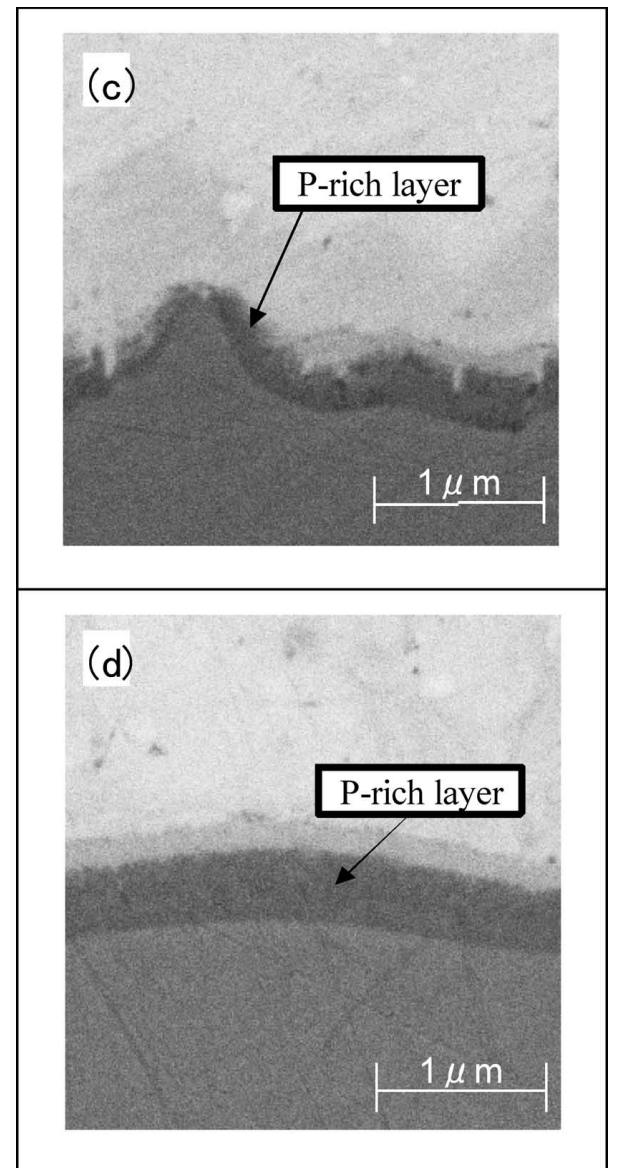

Fig. 5-2 Cross-sectional SEM images of Sn$3.5 \mathrm{Ag}$ solder joint interface for: (c) barrier flux (20,000x); and (d) reference flux (20,000x).

formed by the diffusion of the Ni was reduced by the addition of $\mathrm{Cu}$ to the flux, regardless of the solder composition. It is thought that the decrease in the thickness of this layer, which influences the solder joint strength, is one of the effects that prevent a decrease in joint strength.

We therefore conclude that the $\mathrm{Cu}$ in the flux controlled the diffusion of Sn-Ni during soldering, thus reducing the thickness of the concentrated $\mathrm{P}$ layer and improving the joint strength.

\section{References}

[1] Z. Mei, P. Gallery, D. Fisher, F. Hua and J. Glazer, Advances in Electronic Packaging-1997, 1543 (1997).

[2] S. Sakatani, Y. Kohara, T. Saeki, K. Uenishi and K. F. Kobayashi, 12th Symposium on Microelectronics, 127 (2002).

[3] T. Hiramori, M. Ito, M. Yoshikawa, A. Hirose and K. F. Kobayashi, 12th Symposium on Microelectronics, 
131 (2002).

[4] Y. Chonan, T. Komiyama, J. Onuki, R. Uraao, T. Kimura and T. Nagano, Mater. Trans., 43, 1840 (2002).

[5] N. Torazawa, S. Arai, Y. Takase, K. Sasaki and H. Saka, J. Japan Inst. Metals, 66, 1122 (2002).

[6] C. W. Hwang, K. Suganuma, M. Kiso and S. Hashimoto, J. Mater. Res., 18, 2540 (2003).

[7] C. W. Hwang, K. Suganuma, M. Kiso and S. Hashimoto, J. Electron. Materials, 33, 1200 (2004).

[8] Z. Chen, A. Kumar and M. Mona, J. Electron. Materials, 35, 2126 (2006).

[9] K. Yamomoto, H. Akahoshi, T. Kato, T. Kawamura, R. Kimoto and R. Sato, 12th Symposium on Micro- joining and Assembly Technology in Electronics, 311 (2006).

[10] S. W. Chen and C. H. Wang, J. Mater. Res., 21, 2270 (2006).

[11] C. T. Lim, C. W. Ang, L. B. Tam, S. K. W. Seah and E. H. Wong, 53rd Electronic Components and Technology Conference, 113 (2003).

[12] T. Morita, R. Kajiwara, I. Ueno and S. Okabe, 9th Symposium on Microjoining and Assembly Technology in Electronics, 157 (2003).

[13] A. Yaguchi, M. Yamada and K. Yamamoto, J. Japan Inst. Electron. Packaging, 6, 314 (2003).

[14] T. Morita, I. Ueno, S. Okabe and R. Kajiwara, 82nd Micro Joining, 41 (2006). 